\title{
Chemical characterization of chestnut cultivars from three consecutive years: Chemometrics and contribution for authentication
}

\author{
João C.M. Barreira ${ }^{\mathrm{a}, \mathrm{b}}$, Susana Casal ${ }^{\mathrm{b}}$, Isabel C.F.R. Ferreira ${ }^{\mathrm{a}}$, António M. Peres ${ }^{\mathrm{a}, \mathrm{c}}$, José Alberto Pereira ${ }^{\mathrm{a}, *}$, \\ M. Beatriz P.P. Oliveira ${ }^{\mathrm{b}, *}$ \\ ${ }^{a}$ CIMO-Escola Superior Agrária, Instituto Politécnico de Bragança, Campus de Sta. Apolónia, Apartado 1172, $5301-855$ Bragança, Portugal \\ ${ }^{\mathrm{b}}$ REQUIMTE/Departamento de Ciências Químicas, Faculdade de Farmácia da Universidade do Porto, Rua Jorge Viterbo Ferreira, $n^{\circ} 228,4050-313$ Porto, Portugal

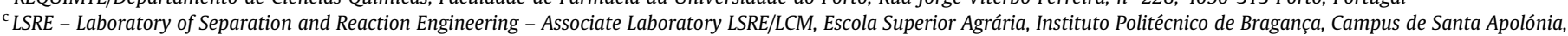 \\ Apartado 1172, 5301-855 Bragança, Portugal
}

\section{A R T I C L E I N F O}

\section{Article history:}

Received 23 January 2012

Accepted 4 April 2012

Available online 16 April 2012

\section{Keywords:}

Castanea sativa Miller

Nutritional/chemical composition

Seasonal variability

Linear discriminant analysis

\begin{abstract}
A B S T R A C T
Four Castanea sativa Miller cultivars (Aveleira, Boaventura, Judia and Longal) belonging to the Protected Designation of Origin "Castanha da Terra Fria", from the Northeast of Portugal, were selected in 2006, 2007 and 2008. Their nutritional, fatty acids, triacylglycerols and tocopherols profiles were evaluated. Water was the major component, followed by carbohydrates, protein and fat, with energetic values lower than $190 \mathrm{kcal} / 100 \mathrm{~g}$ of fresh fruit. Oleic, linoleic and palmitic were the major fatty acids, 1-oleoyl-2-linoleoyl-3-linoleoyl-sn-glycerol, 1-linoleoyl-2-linoleoyl-3-palmitoyl-sn-glycerol, 1-oleoyl-2-linoleoyl-3oleoyl-sn-glycerol and 1-linoleoyl-2-oleoyl-3-palmitoyl-sn-glycerol were the prevalent triacylglycerols and $\gamma$-tocopherol was the most abundant tocopherol. In each parameter, differences between cultivars, harvest year and the possible cultivar $\times$ year interaction were screened through a two-way analysis of variance. Differences among cultivars have been attenuated by the variability among years, leading, in general, to a significant interaction effect, which resulted in a relative homogeneity regarding chemical parameters, showing that nutritional and chemical composition was influenced by seasonal variability. A stepwise linear discriminant model, based on 10 ( $\alpha$-tocopherol, $\gamma$-tocotrienol, LLL, OLLn, $\delta$-tocopherol, $\gamma$-tocopherol, $\delta$-tocotrienol, PLLn, protein and 000) of the 38 initial evaluated variables was also established. The model allowed the complete discrimination of cultivars with overall sensibilities and specificities of $100 \%$, for both original grouped data and leave-one-out cross-validation procedures. Furthermore, similar results were also obtained using only tocopherols data, showing their usefulness as a discriminant factor for chestnut cultivars.
\end{abstract}

(c) 2012 Elsevier Ltd. All rights reserved.

\section{Introduction}

Chestnut fruits stood out for many centuries as one of the most important food resources of the European rural areas, but the

Abbreviations: ADF, acid detergent fiber; ADL, acid detergent lignin; ANOVA, analysis of variance; AOAC, Association of Analytical Communities; DAD, diode array detector; FA, fatty acids; FAME, fatty acids methyl ester; FID, flame ionization detector; GLM, generalized linear model; HSD, honestly significant difference; LDA linear discriminant analysis; LLL, 1,2,3-trilinoleoylglycerol; LLO, 1,2-dilinoleoyl-3oleoyl-rac-glycerol; LLP, 1,2-dilinoleoyl-3-palmitoyl-rac-glycerol; LnLnLn, 1,2,3trilinolenoylglycerol; MCV, means of the canonical variance; NDF, neutral detergent fiber; OOO, 1,2,3-trioleoylglycerol; OOP, 1,2-dioleoyl-3-palmitoyl-rac-glycerol; OOS, 1,2-dioleoyl-3-stearoyl-rac-glycerol; PDO, protected designation of origin; PLO, 1palmitoyl-2-linoleoyl-3-oleoylglycerol; PoPoPo, 1,2,3-tripalmitoleoylglycerol; PPO, 1,2-dipalmitoyl-3-oleoyl-rac-glycerol; PPP, 1,2,3-tripalmitoylglycerol; PUFA, polyunsaturated fatty acids; SSS, 1,2,3-tristearoylglycerol; TAG, triacylglycerols.

* Corresponding authors. Tel.: +351 222078927; fax: +351 222003977 (M.B.P.P. Oliveira), tel.: +351 273303277; fax: +351 273325405 (J.A. Pereira).

E-mail addresses: jpereira@ipb.pt (J.A. Pereira), beatoliv@ff.up.pt (M. Beatriz P.P. Oliveira). emergence of severe chestnut tree diseases and the rural depopulation caused a progressive decline in their production (Adua, 1999). Recently, the growing demand for traditional foods has converted chestnut to an added value resource (Bounous, 2005). Nowadays, chestnut worldwide production is estimated in 1.1 million tons, distributed by a surface with near 340 thousand hectares. From a nutritional point of view, chestnuts have interesting characteristics (Goulão et al., 2001), as it has been supported by other studies on the chemical composition of its kernels, focused on starch, fiber, fat and fatty acids (FA), protein and aminoacids, ash, minerals (Barreira et al., 2009a; Borges et al., 2007; Desmaison et al., 1984; Fernandes et al., 2011; Ferreira-Cardoso et al., 1999; Pereira-Lorenzo et al., 2006a; Senter et al., 1994; Vasconcelos et al., 2007) and vitamins (Barreira et al., 2009b; Vasconcelos et al., 2010).

Currently, consumers are showing an increased interest in these fruits because of their nutritional qualities and potentially beneficial health effects, including the well-known advantages of $\omega-3$ and $\omega-6$ polyunsaturated fatty acids (PUFA), whose intake is 
insufficient in Western diets (Simopoulos, 1991) and of tocopherols (Barreira et al., 2009b). Particularly linoleic acid plays an important role in preventing cardiovascular diseases in adults, promoting the brain and retina development in infants (Simopoulos, 1991; Senter et al., 1994; Künsch et al., 1999) or preventing DNA damage (Kok et al., 2003). FA are condensed as triacylglycerols (TAG) in plant cells. The glycerol molecule does not have rotational symmetry, thereby all the carbon atoms differentiate from each other (Gunstone et al., 1965). Hence, the lipidic fraction of a natural product has a characteristic pattern of TAG, comprising highly specific information due to the genetic control of the stereospecific distribution of FA on the glycerol molecule. In fact, the FA distribution in the glycerol backbone is not random, but typical for each vegetable species (Buchgraber et al., 2004). The position of FA in the TAG molecules has also a significant impact on their metabolism in the body (McKenna et al., 1985). Accordingly the characterization of a determined lipidic fraction should always include FA and TAG analysis.

Vitamin E is an important lipophilic antioxidant which showed positive effects in living systems counteracting aging (Agostinucci et al., 2002), strengthening the immune system and reducing cancer risk (Lee and Wan, 2000), reducing viral load in HIV-infected persons (Allard et al., 1998) or in the treatment of Parkinsonsyndrome (Itoh et al., 2006).

Chestnuts show high variability in their chemical characterization, mainly due to harvesting year (Pinnavaia et al., 1993; Sacchetti and Pinnavaia, 2005; Neri et al., 2010). The seasonal variability has been reported in Portuguese (Ferreira-Cardoso et al., 2005) and Italian (Neri et al., 2010) cultivars, but additional studies are still necessary for a better comprehension. Therefore, the aim of this work was to perform the chemical characterization of selected cultivars (Aveleira, Boaventura, Judia and Longal) in three consecutive years to find distinctive features useful for the authentication of a specific chestnut cultivar, offering an important economical advantage.

\section{Materials and methods}

\subsection{Standards and reagents}

All reagents were of analytical grade: methanol and diethyl ether were supplied by Lab-Scan (Lisbon, Portugal), toluene from Riedel-de-Haen (Seelze, Germany) and sulfuric acid from Fluka (Madrid, Spain). The fatty acids methyl ester (FAME) reference standard (47885-U) mixture (37 fatty acids C4 to C24) was from Supelco (Bellefonte, PA) and purchased to Sigma (St. Louis, MO), as well as other individual fatty acids isomers.

TAG: 1,2,3-tripalmitoylglycerol (PPP), 1,2,3-tristearoylglycerol (SSS), 1,2,3-trilinolenoylglycerol (LnLnLn), and 1,2,3-tripalmitoleoylglycerol (PoPoPo), of purity $>98 \%$, and 1,2,3-trioleoylglycerol (OOO), 1,2,3-trilinoleoylglycerol (LLL), 1,2dilinoleoyl-3-palmitoyl-rac-glycerol (LLP), 1,2-dilinoleoyl-3-oleoyl-rac-glycerol (LLO), 1,2-dipalmitoyl-3-oleoyl-rac-glycerol (PPO), 1,2-dioleoyl-3-stearoyl-racglycerol (OOS), 1-palmitoyl-2-linoleoyl-3-oleoylglycerol (PLO), and 1,2-dioleoyl-3palmitoyl-rac-glycerol (OOP), of $\approx 99 \%$ purity, were purchased from Sigma (St. Louis, MO). Acetonitrile and acetone were of HPLC grade and obtained from Merck (Darmstadt, Germany). Tocopherols and tocotrienols $(\alpha, \beta, \gamma$ and $\delta$ ) were purchase from Calbiochem (La Jolla, San Diego, CA). 2-Methyl-2-(4,8,12-trimethyltridecyl)chroman-6-ol (tocol) (Matreya Inc., Pleasant Gap, PA) was used as internal standard (IS). Butylated hydroxytoluene (BHT) was obtained from Aldrich (Madrid, Spain), hexane was of HPLC grade from Merck (Darmstad, Germany) and 1,4-dioxane was from Fluka (Madrid, Spain). All the other chemicals were of analytical grade and obtained from Sigma Chemical Co. (St. Louis, MO). Water was treated in a MiliQ water purification system (TGI Pure Water Systems, Brea, CA).

\subsection{Samples and sample preparation}

All the samples belong to the Protected Designation of Origin (PDO) "Castanha da Terra Fria". This PDO was created in 1994, with the normative decree 44/94 from February 3rd, where it is defined as the fruit obtained from Castanea sativa, including the varieties Longal, Judia, Amarelal, Lamela, Aveleira, Boaventura, Trigueira, Martainha and Negral (Portuguese Government Legislation, 1994: Decreto Normativo 44/94). Fruits were randomly collected from five different trees per each cultivar, used in a previous study (Barreira et al., 2009a), being equally prepared. The same representative trees were selected during the harvesting years of 2006, 2007 and 2008.

The assays were carried out in duplicate, using $50 \mathrm{~g}$ in each case, obtaining ten results per cultivar per year. The results are expressed as mean values \pm standard deviation (SD). Fruits were obtained in orchards located in the geographical region of Vinhais (Trás-os-Montes), in the Northeast of Portugal: Aveleira, $41^{\circ} 49^{\prime} \mathrm{N}, 7^{\circ} 01$ O; Boaventura, $41^{\circ} 51^{\prime} \mathrm{N}, 7^{\circ} 01^{\prime} \mathrm{O}$; Judia, $41^{\circ} 50^{\prime} \mathrm{N}, 7^{\circ} 01^{\prime} \mathrm{O}$; Longal, $41^{\circ} 50^{\prime} \mathrm{N}, 7^{\circ} 00^{\prime} \mathrm{O}$ ), from cultivars belonging to the PDO "Castanha da Terra Fria". Chestnut fruits were kept at $-20^{\circ} \mathrm{C}$ and protected from light until further use. Immediately before the extraction procedure, each sample was manually peeled off (inner and outer skins).

\subsection{Proximate analysis}

Chestnut samples were analyzed for chemical composition (water, protein, fat, ash and fiber) using the Association of Analytical Communities (AOAC) procedures (AOAC, 1995). Protein (macroKjeldahl method; $N \times 5,30$ ), fat (Universal extraction system B-811, with petroleum ether), ash (incineration at $550 \pm 15^{\circ} \mathrm{C}$ ), carbohydrates (by difference) and fiber were determined using dried chestnut samples following the procedures already described in a previous study (Barreira et al., 2009a). Neutral detergent fiber (NDF), including cellulose, hemicelluloses and lignin, acid detergent fiber (ADF), including cellulose and lignin less digestible and woody fibers and acid detergent lignin (ADL) were determined according to Robertson and Van Soest method (Robertson and Van Soest, 1981).

\subsection{Fatty acids analysis}

FAME were prepared by hydrolysis with a $2 \mathrm{M}$ methanolic potassium hydroxide solution, and extraction with $n$-heptane, in accordance with ISO 5509 method (ISO 2000) and following a procedure described in a previous work (Barreira et al., 2009a). The fatty acids profile was evaluated with a Chrompack CP 9001 chromatograph (Chrompack, Middelburg, Netherlands) equipped with a split-splitless injector, a flame ionization detector (FID), and a Chrompack CP-9050 auto-sampler. Separation was achieved on a $50 \mathrm{~m} \times 0.25 \mathrm{~mm}$ i.d. fused silica capillary column coated with a $0.19 \mu \mathrm{m}$ film of CP-Sil 88 (Chrompack). Helium was used as carrier gas at an internal pressure of $120 \mathrm{kPa}$. The results are expressed in relative percentage of each fatty acid, calculated by internal normalization of the chromatographic peak area, and assuming that the detector response was the same for all compounds.

\subsection{Triacylglycerol analysis}

The chromatographic analyzes were performed according to the procedure previously described (Barreira et al., 2009a), with a Jasco (Tokyo, Japan) high-pressure liquid chromatograph, equipped with a PU-1580 quaternary pump and a Jasco AS950 automatic sampler with a $10 \mu \mathrm{L}$ loop. Detection was performed with an evaporative light-scattering detector (ELSD) (model 75-Sedere, Alfortville, France). Taking into account the selectivities ( $R$, relative retention times to LLL), peaks were identified according to the logarithms of $\mathrm{R}$ in relation to homogeneous TAG. Quantification of the peaks was made by internal normalization of chromatographic peak area, and the results are expressed in relative percentage, assuming that the detector response was the same for all compounds.

\subsection{Tocopherols analysis}

The selected HPLC equipment consisted of an integrated system with a PU-980 pump, an AS-950 auto-sampler, an MD-910 multiwavelenght diode array detector (DAD) connected in series with an FP-920 fluorescence detector (Jasco, Japan) programmed for excitation at $290 \mathrm{~nm}$ and emission at $330 \mathrm{~nm}$, gain 10. Data were analyzed using Borwin-PDA Controller Software (JMBS, France). The chromatographic separation was achieved following the procedure previously described (Barreira et al., 2009b). The compounds were identified by chromatographic comparisons with authentic standards and by their UV spectra. Quantification was based on the fluorescence signal response, using the internal standard method.

\subsection{Statistical analysis}

An analysis of variance (ANOVA) with Type III sums of squares was performed using the GLM (Generalized Linear Model) procedure of the SPSS software, version 18.0 (SPSS, Inc.). All dependent variables were analyzed using a 2-way ANOVA, considering the factors " $C$. sativa cultivar" and "harvesting year". If a statistical significant interaction effect ("C. sativa cultivar $\times$ harvesting year") was found, the two factors were evaluated simultaneously by plotting the estimated marginal means for all levels of each factor. Otherwise, for each statistical significant factor, means were compared using Tukey's honestly significant difference (HSD) multiple comparison test. In addition, a linear discriminant analysis (LDA) was used as a supervised learning technique to classify the four $C$. sativa cultivars according to their nutritional, FA, TAG and tocopherols contents. A stepwise technique, using the Wilks' $\lambda$ method with the usual probabilities of $F$ ( 3.84 to enter and 2.71 to remove), 
was applied for variable selection. This procedure uses a combination of forward selection and backward elimination procedures, where before selecting a new variable to be included, it is verified whether all variables previously selected remain significant (Rencher, 1995; Maroco, 2003; López et al., 2008). With this approach, it is possible to identify the significant variables among the nutritional, FA, TAG and tocopherols profiles obtained for each sample. To verify which canonical discriminant functions were significant, the Wilks' $\lambda$ test was applied. To avoid overoptimistic data modulation, a leaving-one-out cross-validation procedure was carried out to assess the model performance.

Moreover, the sensibility and specificity of the discriminant model were computed from the number of individuals correctly predicted as belonging to an assigned group (Rencher, 1995; López et al., 2008). Sensibility was calculated by dividing the number of samples of a specific group correctly classified by the total number of samples belonging to that specific group. Specificity was calculated by dividing the number of samples of a specific group classified as belonging to that group by the total number of samples of any group classified as belonging to that specific group. The LDA statistical analysis and the other statistical tests were performed at a 5\% significance level using the SPSS software, 18.0 (SPSS Inc.).

\section{Results and discussion}

\subsection{Proximate analysis}

Table 1 shows the proximate composition data reported as mean value of each cultivar over three harvesting years as well as mean value of all cultivars within each harvesting year. The results show that chestnuts cultivar $\times$ harvesting year was a significant $(P \leqslant 0.011)$ source of variation for all proximate data composition evaluated, showing that seasonal variability play an important role in the cultivar proximate composition. Thus, although the least squares means are presented for the main effects, no multiple comparisons were performed.

Moreover, both factors (cultivar and harvesting year) show a significant effect, except harvesting year for crude protein content $(P=0.373)$ and cultivar effect for cellulose $(P=0.053)$. Nevertheless, from the analysis of the plots of the estimated margins means (data not shown), for each proximate variable, some general conclusions can be drawn. For instance, fat, carbohydrates, and consequently energy levels, were greater in 2006 (except for Boaventura); water content was lower in 2006 (except for Boaventura); protein content was higher in 2008 (except for Judia); ash contents were lower in 2006. Considering cultivar variation, Aveleira tended to have higher fat (except in 2008) and protein contents; Judia and Longal leaned to have superior ash contents. It was not observed any particular tendency, regarding water content, carbohydrates and energy. Generally, the acquired results categorized water as the major component, high amounts of carbohydrates (mainly due to the high starch content), crude protein as the second nutrient (but with rather lower amounts) and very low fat levels (less than $0.9 \%$ ), demonstrating a similar profile when compared with other chestnut Portuguese cultivars from different geographical origins (Borges et al., 2008). In view of the resemblance among nutritional parameters, the energetic values are fairly identical. Ash contents laid under 1.2\%. Regarding fiber composition, the analysis was performed separating NDF, or cell wall, which consists of hemicellulose, cellulose and lignin; ADF, that consists mainly of cellulose and lignin; ADL, which is measured by further treating ADF with strong acid, which dissolves cellulose, or with permanganate, which oxidizes (removes) the lignin; and cellulose. ADL amounts were lower than $0.1 \mathrm{~g} / 100 \mathrm{~g}$ fresh weight; thereby these data are not included. Regarding interannual variability, NDF was higher in 2007; ADF and cellulose were tendencially superior in 2008 (except for Aveleira in both cases). Aveleira seemed to have higher NDF, ADF and cellulose contents (except in 2008 for all cases). In general, chestnut revealed relative high fibers amounts, as it has already been defined by previous studies (Vaughan and Geissler, 1997; Barreira et al., 2009a), a feature that can explain the beneficial effects of its consumption on human health, once fibers had already been reported as an important cardiovascular disease risk reduction factor, having also a preventive role in certain cancers and the ability of lowering plasma cholesterol (Camire and Dougherty, 2003).

The obtained results are in agreement with previous works, taking into consideration the corresponding basis (fresh or dry) at which the results are presented (Desmaison et al., 1984; De La Montaña Míguelez et al., 2004; Pereira-Lorenzo et al., 2006a; Gonçalves et al., 2010; Borges et al., 2008).

\subsection{Fatty acids analysis}

Table 2 shows the fatty acids profiles data reported as mean value of each cultivar over three harvesting years as well as mean value of all cultivars within each harvesting year. The results show that chestnuts cultivar $\times$ harvesting year was a significant source of variation for the majority of fatty acids $(P \leqslant 0.012)$, but not for C16:1 $(P=0.097), C 18: 0(P=0.066), C 20: 1(P=0.073)$ and PUFA $(P=0.091)$. The factor cultivar had no significant influence on C16:0 $(P=0.916), \quad C 18: 0 \quad(P=0.340), C 18: 1 \quad(P=0.400), \quad C 18: 2$ $(P=0.719)$, MUFA $(P=0.424)$ and PUFA $(P=0.080)$.

However, the factor year showed a significant effect for all fatty acids $(P<0.001)$, once more indicating that the seasonal variability exerts an important influence over chestnut chemical profiles. In fact, the performed multiple comparisons revealed differences among years, but some similarity among cultivars. The analysis of the plots of the estimated margins means (data not shown) for each proximate variable complemented these conclusions. Independently of harvesting year, C16:0 (except for 2007) and C16:1 tended to be higher in Aveleira, as well as C18:0 (except for 2007) in Boaventura; C17:0 (except for 2008), C18:2 (except for 2007), C18:3 (except for 2007), C20:1 and C22:0 (except for 2008) were tendentiously higher in Longal. In other way, C17:0 (except for Aveleira), C18:2, C18:3 (except for Aveleira) and C20:1 were higher in 2006. In 2007, the occurrence of C16:0, C16:1, C18:0, C18:1 (except for Aveleira), C20:0 (except for Boaventura) and C22:0 were also more elevated. Nonetheless, those results

Table 1

Proximate composition (g/100 g fresh weight) and corresponding energy (per $100 \mathrm{~g}$ ). The results are presented as mean \pm SD ( $n=20$, for each year; $n=15$ for each cultivar).

\begin{tabular}{|c|c|c|c|c|c|c|c|c|c|c|}
\hline & & Water & Crude fat & Crude protein & Carbohydrates & NDF & $\mathrm{ADF}$ & Cellulose & Ash & Energy (kcal) \\
\hline \multirow[t]{5}{*}{ Cultivar } & Aveleira & $53 \pm 1$ & $0.8 \pm 0.1$ & $3.0 \pm 0.3$ & $42 \pm 1$ & $1.6 \pm 0.3$ & $0.25 \pm 0.03$ & $0.24 \pm 0.03$ & $0.9 \pm 0.2$ & $189 \pm 4$ \\
\hline & Boaventura & $54 \pm 1$ & $0.7 \pm 0.1$ & $2.4 \pm 0.1$ & $42.0 \pm 0.4$ & $1.7 \pm 0.1$ & $0.26 \pm 0.03$ & $0.25 \pm 0.04$ & $0.8 \pm 0.1$ & $184 \pm 2$ \\
\hline & Judia & $54 \pm 1$ & $0.8 \pm 0.1$ & $2.7 \pm 0.3$ & $42 \pm 1$ & $1.5 \pm 0.2$ & $0.25 \pm 0.02$ & $0.23 \pm 0.04$ & $1.1 \pm 0.2$ & $184 \pm 5$ \\
\hline & Longal & $53 \pm 2$ & $0.7 \pm 0.1$ & $2.6 \pm 0.2$ & $43 \pm 2$ & $1.5 \pm 0.2$ & $0.25 \pm 0.04$ & $0.24 \pm 0.04$ & $1.1 \pm 0.2$ & $188 \pm 7$ \\
\hline & $P$-value & 0.030 & $<0.001$ & $<0.001$ & 0.011 & $<0.001$ & 0.011 & 0.053 & $<0.001$ & 0.002 \\
\hline \multirow[t]{4}{*}{ Year } & 2006 & $53 \pm 1$ & $0.80 \pm 0.05$ & $2.7 \pm 0.4$ & $43 \pm 1$ & $1.6 \pm 0.2$ & $0.25 \pm 0.02$ & $0.25 \pm 0.02$ & $0.8 \pm 0.1$ & $189 \pm 6$ \\
\hline & 2007 & $54 \pm 1$ & $0.7 \pm 0.1$ & $2.6 \pm 0.2$ & $42 \pm 1$ & $1.8 \pm 0.1$ & $0.24 \pm 0.02$ & $0.21 \pm 0.03$ & $1.1 \pm 0.1$ & $184 \pm 6$ \\
\hline & 2008 & $53 \pm 1$ & $0.7 \pm 0.1$ & $2.7 \pm 0.3$ & $42 \pm 1$ & $1.4 \pm 0.2$ & $0.27 \pm 0.04$ & $0.26 \pm 0.04$ & $1.1 \pm 0.2$ & $185 \pm 3$ \\
\hline & $P$-value & 0.001 & $<0.001$ & 0.373 & 0.004 & $<0.001$ & $<0.001$ & $<0.001$ & $<0.001$ & 0.001 \\
\hline Cultivar $\times$ year & $P$-value & 0.011 & $<0.001$ & $<0.001$ & 0.003 & $<0.001$ & $<0.001$ & $<0.001$ & $<0.001$ & 0.011 \\
\hline
\end{tabular}


demonstrated that chestnut lipidic fraction is mainly constituted by three fatty acids: linoleic, oleic and palmitic acids accounting for more than $90 \%$ of the total FA content, a value slightly higher when compared with the results obtained by other research groups (Borges et al., 2007), most likely due to the different origin of chestnut samples. In addition to these three main fatty acids, 11 more were identified, with special relevance to linolenic acid. C14:0, $\mathrm{C} 15: 0, \mathrm{C} 17: 1$ and $\mathrm{C} 24: 0$ were detected in residual amounts $(<0.2 \%)$ and therefore excluded from Table 2. SFA formation appeared to be superior in Aveleira (except in 2007) and during 2007 (except for Longal); palmitic acid was clearly the most important SFA with values ranging from $14.6 \%$ to $20.1 \%$ among years and 16.4-16.9\% between cultivars, of total fatty acids. MUFA were not privileged for any cultivar, but showed some seasonal prevalence in 2007; oleic acid is the most abundant, varying from $33.5 \%$ to $39.3 \%$ among years and $34.9 \%$ to $36.9 \%$ between cultivars, of total fatty acids content. PUFA seemed to be favored for Longal cultivar (except in 2007) and for 2006 year (except for Aveleira); linolenic acid was evidently the major PUFA, with contents ranging from $32.3 \%$ to $43.1 \%$ among years and $37.9 \%$ to $39.8 \%$ between cultivars, of total fatty acids. The high amount of this PUFA represents a well known advantage, since it is classified as an essential fatty (Emken et al., 1994).

In general, the results obtained after calculating three years' mean seemed to reveal that any specific differences between cultivars were overcome by the seasonal variability. Even if the results are considered as the sum of SFA, MUFA or PUFA, the only statistical differences were found for PUFA content in 2007.

\subsection{Triacylglycerols analysis}

Table 3 shows the TAG profiles data reported as mean value of each cultivar over three harvesting years as well as mean value of all cultivars within each harvesting year. Thirteen compounds were determined in chestnuts: LLnLn, LLLn, LLL, OLLn, PLLn, LLO, PLL, OLO, PLO, PLP, OOO, POO and PPO (L, linoleoyl; Ln, linolenoyl, $\mathrm{P}$, palmitoyl; O, oleoyl). The results show that chestnuts cultivar $\times$ harvesting year was a significant $(P \leqslant 0.002)$ source of variation for all the assayed TAG.

Thus, although the least squares means are presented for the main effects no multiple comparisons are performed. Furthermore, both factors show a significant effect, except harvesting year for LLLn $(P=0.260)$, OLLn $(P=0.248)$, PLO $(P=0.463)$ and 000 $(P=0.229)$ contents. Even so, from the analysis of the plots of the estimated margins means, some general conclusions can be drawn.

Independently of harvesting year, PLO tended to be higher in Aveleira, OOO and POO leaned to be larger in Boaventura, OLLn was relatively higher in Judia and LLLn and PLLn, were superior in Longal. In 2006, the occurrence of LLL and PLLn (except for Aveleira) seemed to be favored; OLLn (except for Boaventura), PLO (except for Aveleira), PLP (except for Aveleira) were more abundant in 2007. The remaining fatty acids revealed erratic behaviors either for year and cultivar.

LLO was the main component in cultivars (22.7-25.6\%) and years (23.3-24.5\%). In addition to LLO, the three major TAGs were PLL, OLO and PLO, with contents superior to $12 \%$, in all chestnut samples and harvesting years. OOO, LLL, POO were also present in significant amounts, once more reflecting the fatty acids profile. Actually, considering the quantified TAGs, all of them contain, at least, one linoleic acid or one oleic acid molecule. LLnLn and PPO were present in minute amounts (inferior to $0.50 \%$ ) and were not included in Table 3. Nevertheless, all cultivars presented common features, defining a chemical fingerprint that may be useful for evaluate the quality of chestnut fruits. Actually, the specificity of TAG profile is being progressively used in the food industry as a tool to assess quality and authenticity of vegetable oils, determining its origin or detecting adulterations (Kamm et al., 2001).

\subsection{Tocopherols and tocotrienols analysis}

Table 4 shows the tocopherols and tocotrienols profiles data reported as mean value of each cultivar over three harvesting years as well as mean value of all cultivars within each harvesting year. The results show that chestnuts cultivar $\times$ harvesting year acts as a significant source of variation only for $\gamma$-tocotrienol $(P<0.001)$ and $\alpha$-tocopherol $(P=0.002)$. The factor cultivar showed a significant effect for all vitamers, but year effect was only significant for $\gamma$ tocotrienol and $\gamma$-tocopherol.

The performed multiple comparisons highlighted some differences among cultivars. After the analysis of the plots of the estimated margins means (data not shown), other general conclusions could be obtained for each tocopherol. Actually, chromatographic analysis revealed the presence of five of the eight vitamin $\mathrm{E}$ isoforms. $\gamma$-Tocopherol was the major compound in a very high extent, and vitamin E profile was similar along all the assayed cultivars $(\gamma$-tocopherol $>>>\gamma$-tocotrienol $>\delta$-tocopherol $>\alpha$ tocopherol $>\delta$-tocotrienol), except Boaventura: $(\gamma$-tocopherol $>>>$ $\delta$-tocopherol $>\gamma$-tocotrienol $>\alpha$-tocopherol $>\delta$-tocotrienol), confirming the obtained profiles for one single year (Barreira et al., 2009b). Longal had higher quantities of all the vitamers (except for $\gamma$-tocopherol in 2006). The differences detected for this cultivar, which the most appreciated regarding organoleptic characteristics, are also observed for other compounds, like starch (Pereira-Lorenzo et al., 2006a; Ferreira-Cardoso et al., 1993) and also for their morphology (Pereira-Lorenzo et al., 2006b). Diversely, the harvesting year plots of the estimated margins means were practically coincident, despite some statistical differences found for $\gamma$-tocopherol that revealed higher values in 2008. In fact, it became clear that tocopherol profiles could have some discriminant power among cultivars. This hypothesis was subsequently confirmed

Table 2

Fatty acids composition ( $\mathrm{g} / 100 \mathrm{~g}$ of fatty acids). The results are presented as mean \pm SD ( $n=20$, for each year; $n=15$ for each cultivar).

\begin{tabular}{|c|c|c|c|c|c|c|c|c|c|c|c|c|c|c|}
\hline & & C16:0 & C16:1 & C17:0 & C18:0 & C18:1 & C18:2 & C18:3 & C20:0 & C20:1 & $\mathrm{C} 22: 0$ & SFA & MUFA & PUFA \\
\hline \multirow[t]{5}{*}{ Cultivar } & Aveleira & $17 \pm 1$ & $0.5 \pm 0.2^{\mathrm{a}}$ & $0.15 \pm 0.02$ & $1.1 \pm 0.1$ & $35 \pm 3$ & $40 \pm 3$ & $4 \pm 1$ & $0.44 \pm 0.05$ & $0.7 \pm 0.1^{\mathrm{b}}$ & $0.33 \pm 0.04$ & $19 \pm 1$ & $37 \pm 3$ & $44 \pm 4$ \\
\hline & Boaventura & $16 \pm 2$ & $0.5 \pm 0.1^{\mathrm{b}}$ & $0.18 \pm 0.05$ & $1.2 \pm 0.2$ & $37 \pm 3$ & $38 \pm 5$ & $5 \pm 1$ & $0.4 \pm 0.1$ & $0.71 \pm 0.04^{b}$ & $0.30 \pm 0.05$ & $19 \pm 3$ & $38 \pm 4$ & $43 \pm 6$ \\
\hline & Judia & $17 \pm 4$ & $0.4 \pm 0.1^{\mathrm{b}}$ & $0.2 \pm 0.1$ & $1.1 \pm 0.3$ & $35 \pm 6$ & $40 \pm 9$ & $5 \pm 1$ & $0.4 \pm 0.1$ & $0.7 \pm 0.1^{\mathrm{b}}$ & $0.3 \pm 0.1$ & $19 \pm 5$ & $36 \pm 6$ & $45 \pm 10$ \\
\hline & Longal & $17 \pm 5$ & $0.4 \pm 0.1^{\mathrm{b}}$ & $0.2 \pm 0.1$ & $1.2 \pm 0.5$ & $35 \pm 7$ & $39 \pm 11$ & $5 \pm 2$ & $0.43 \pm 0.05$ & $0.80 \pm 0.04^{a}$ & $0.3 \pm 0.1$ & $16 \pm 2$ & $36 \pm 7$ & $48 \pm 7$ \\
\hline & $P$-value & 0.916 & $<0.001$ & 0.012 & 0.340 & 0.400 & 0.719 & 0.041 & 0.002 & $<0.001$ & 0.006 & $<0.001$ & 0.424 & 0.080 \\
\hline \multirow[t]{4}{*}{ Year } & 2006 & $15 \pm 1$ & $0.3 \pm 0.1^{\mathrm{c}}$ & $0.2 \pm 0.1$ & $0.9 \pm 0.1^{b}$ & $34 \pm 4$ & $42 \pm 3$ & $6 \pm 1$ & $0.36 \pm 0.05$ & $0.8 \pm 0.1^{\mathrm{a}}$ & $0.28 \pm 0.05$ & $17 \pm 1$ & $35 \pm 3$ & $48 \pm 4^{\mathrm{a}}$ \\
\hline & 2007 & $20 \pm 4$ & $0.6 \pm 0.1^{\mathrm{a}}$ & $0.2 \pm 0.1$ & $1.4 \pm 0.5^{\mathrm{a}}$ & $39 \pm 6$ & $32 \pm 9$ & $4 \pm 1$ & $0.5 \pm 0.1$ & $0.7 \pm 0.1^{b}$ & $0.4 \pm 0.1$ & $20 \pm 5$ & $41 \pm 6$ & $39 \pm 8^{\mathrm{b}}$ \\
\hline & 2008 & $15 \pm 1$ & $0.5 \pm 0.1^{\mathrm{b}}$ & $0.14 \pm 0.02$ & $1.1 \pm 0.2^{\mathrm{b}}$ & $33 \pm 2$ & $43 \pm 2$ & $5 \pm 1$ & $0.44 \pm 0.05$ & $0.7 \pm 0.1^{\mathrm{b}}$ & $0.3 \pm 0.1$ & $17 \pm 2$ & $35 \pm 2$ & $48 \pm 3^{a}$ \\
\hline & $P$-value & $<0.001$ & $<0.001$ & $<0.001$ & $<0.001$ & $<0.001$ & $<0.001$ & $<0.001$ & $<0.001$ & $<0.001$ & $<0.001$ & $<0.001$ & $<0.001$ & $<0.001$ \\
\hline Cultivar $\times$ year & $P$-value & $<0.001$ & 0.097 & 0.012 & 0.066 & 0.001 & 0.001 & $<0.001$ & 0.003 & 0.073 & $<0.001$ & $<0.001$ & 0.002 & 0.091 \\
\hline
\end{tabular}

In each column and for each cultivar, different letters mean significant differences $(P<0.05)$. 
Table 3

Triacylglycerol composition (g/100 g TAG).The results are presented as mean \pm SD $(n=20$, for each year; $n=15$ for each cultivar).

\begin{tabular}{|c|c|c|c|c|c|c|c|c|c|c|c|c|}
\hline & & LLLn & LLL & OLLn & PLLn & LLO & PLL & OLO & PLO & PLP & 000 & POO \\
\hline \multirow[t]{5}{*}{ Cultivar } & Aveleira & $2 \pm 1$ & $4 \pm 1$ & $2 \pm 1$ & $2 \pm 1$ & $23 \pm 4$ & $17 \pm 3$ & $16 \pm 2$ & $17 \pm 3$ & $2 \pm 1$ & $8 \pm 3$ & $6 \pm 2$ \\
\hline & Boaventura & $3 \pm 1$ & $9 \pm 2$ & $3 \pm 1$ & $1.8 \pm 0.5$ & $23 \pm 1$ & $14 \pm 3$ & $15 \pm 3$ & $14 \pm 1$ & $2 \pm 1$ & $11 \pm 1$ & $6 \pm 1$ \\
\hline & Judia & $3 \pm 1$ & $10 \pm 1$ & $4 \pm 1$ & $1.8 \pm 0.3$ & $25 \pm 1$ & $15 \pm 2$ & $14 \pm 2$ & $14 \pm 2$ & $1.4 \pm 0.7$ & $8 \pm 2$ & $4 \pm 1$ \\
\hline & Longal & $4 \pm 1$ & $10 \pm 1$ & $4 \pm 1$ & $3 \pm 1$ & $26 \pm 2$ & $17 \pm 1$ & $15 \pm 2$ & $12 \pm 1$ & $1.2 \pm 0.4$ & $5 \pm 1$ & $2.9 \pm 0.4$ \\
\hline & $P$-value & $<0.001$ & $<0.001$ & $<0.001$ & $<0.001$ & $<0.001$ & $<0.001$ & 0.017 & $<0.001$ & 0.002 & $<0.001$ & $<0.001$ \\
\hline \multirow[t]{4}{*}{ Year } & 2006 & $2 \pm 1$ & $7 \pm 3$ & $3 \pm 1$ & $2 \pm 1$ & $23 \pm 3$ & $16 \pm 2$ & $16 \pm 2$ & $15 \pm 4$ & $1.2 \pm 0.5$ & $8 \pm 3$ & $5 \pm 2$ \\
\hline & 2007 & $3 \pm 1$ & $9 \pm 3$ & $3 \pm 1$ & $2 \pm 1$ & $24 \pm 2$ & $15 \pm 3$ & $14 \pm 3$ & $14 \pm 2$ & $2 \pm 1$ & $8 \pm 3$ & $4 \pm 2$ \\
\hline & 2008 & $2.6 \pm 0.4$ & $9 \pm 3$ & $3 \pm 1$ & $1.7 \pm 0.5$ & $24 \pm 2$ & $16 \pm 2$ & $15 \pm 1$ & $14 \pm 3$ & $2 \pm 2$ & $8 \pm 2$ & $4 \pm 1$ \\
\hline & $P$-value & 0.260 & $<0.001$ & 0.248 & 0.001 & 0.012 & 0.016 & 0.001 & 0.463 & $<0.001$ & 0.229 & 0.025 \\
\hline Cultivar $\times$ year & $P$-value & 0.007 & $<0.001$ & $<0.001$ & 0.002 & $<0.001$ & $<0.001$ & $<0.001$ & $<0.001$ & $<0.001$ & $<0.001$ & $<0.001$ \\
\hline
\end{tabular}

Table 4

Tocopherol composition (ng/g of fresh fruit). The results are presented as mean $\pm \operatorname{SD}(n=20$, for each year; $n=15$ for each cultivar).

\begin{tabular}{|c|c|c|c|c|c|c|}
\hline & & $\alpha$-Tocopherol & $\gamma$-Tocopherol & $\gamma$-Tocotrienol & $\delta$-Tocopherol & $\delta$-Tocotrienol \\
\hline \multirow[t]{5}{*}{ Cultivar } & Aveleira & $23 \pm 4$ & $4329 \pm 219^{b}$ & $332 \pm 22$ & $218 \pm 19^{b}$ & $20 \pm 6^{b}$ \\
\hline & Boaventura & $28 \pm 5$ & $3836 \pm 238^{c}$ & $197 \pm 28$ & $272 \pm 19^{a}$ & $14 \pm 2^{c}$ \\
\hline & Judia & $38 \pm 5$ & $4604 \pm 293^{\mathrm{a}}$ & $313 \pm 67$ & $216 \pm 8^{b}$ & $16 \pm 2^{\mathrm{c}}$ \\
\hline & Longal & $100 \pm 10$ & $4572 \pm 428^{\mathrm{a}, \mathrm{b}}$ & $399 \pm 47$ & $285 \pm 32^{a}$ & $32 \pm 4^{\mathrm{a}}$ \\
\hline & $P$-value & $<0.001$ & $<0.001$ & $<0.001$ & $<0.001$ & $<0.001$ \\
\hline \multirow[t]{4}{*}{ Year } & 2006 & $46 \pm 28$ & $4210 \pm 251^{\mathrm{b}}$ & $271 \pm 81$ & $243 \pm 38$ & $21 \pm 10$ \\
\hline & 2007 & $48 \pm 35$ & $4327 \pm 538^{\mathrm{a}, \mathrm{b}}$ & $322 \pm 81$ & $251 \pm 40$ & $21 \pm 7$ \\
\hline & 2008 & $48 \pm 33$ & $4469 \pm 431^{\mathrm{a}}$ & $338 \pm 83$ & $249 \pm 36$ & $20 \pm 8$ \\
\hline & $P$-value & 0.624 & 0.021 & $<0.001$ & 0.481 & 0.847 \\
\hline Cultivar $\times$ year & $P$-value & 0.002 & 0.187 & $<0.001$ & 0.684 & 0.668 \\
\hline
\end{tabular}

In each column and for each cultivar, different letters mean significant differences $(P<0.05)$.

(see Section 3.5 Linear discriminant analysis), especially for Longal cultivar, which presented generally higher amounts of the five detected vitamers. Despite these inter-cultivar differences, chestnuts present a qualitative vitamin E profile quite dissimilar from other related foods like almond or hazelnut, but very related to other like walnut, pistachios or pecans (Kormsteiner et al., 2006).

Overall, chestnuts have low caloric value, with values below $190 \mathrm{kcal} / 100 \mathrm{~g}$ of fresh weight. The relative high fibers amounts can also increase the beneficial effects of chestnut consumption on human health. The FA profiles were quite analogous for all the cultivars, with the isomers cis-9-octadecenoate (C18:1 $\omega 9$ ), cis-9,12-octadecadienoate (C18:2 $\omega 6$ ) and palmitic acid (C16:0) as largely major compounds, highlighting chestnuts as health-promoting foods. In general, the contents in unsaturated fatty acids tended to be lower in 2007. The C18 unsaturated fatty acids are particularly important and govern, to a large degree, the physical properties of the oils and their practical applications and commercial values (Gunstone et al., 1965). The main components in TAG profiles were LLO, PLL, OLO and PLO, reflecting the high content of oleic, linoleic and palmitic acids. The high $\gamma$-tocopherol dominance may represent an important feature, since this vitamer is known for its anti-inflammatory activity (Jiang et al., 2000).

In fact, these results confirm that chestnuts are a good source of healthy compounds, enhancing chestnut commercial value. The substitution of phytotherapeutics by natural products with bioactive compounds in many industrial formulations can provide very consistent advantages, first of all at the biocompatibility level and also for the environment preservation (Baraldi et al., 2007).

\subsection{Linear discriminant analysis (LDA)}

The results were evaluated through LDA to evaluate which were the most discriminative variables for cultivars differentiation. All independent variables selected by the stepwise procedure of the discriminant analysis complied with the tolerance level of $1-R^{2}$
$>0.6$ and were statistically significant according to the Wilks' $\lambda$ test $(P<0.05)$.

The LDA was performed considering different sets of the assayed parameters, in order to find which one discriminates better chestnut cultivars. In this analysis, several combinations of the obtained results were used, but data regarding nutritional parameters, FA and TAG are not shown, due to their lack of effectiveness.

When all the parameters (nutritional, FA, TAG and tocopherols) were initially considered and assayed, the stepwise LDA resulted in a discriminant model with three significant $(P<0.001$ for the Wil$\mathrm{ks}$ ' $\lambda$ test) discriminant functions. These three functions explained $100.0 \%$ of the variance of the experimental data (the first explained $73.5 \%$, the second $18.1 \%$ and the third $8.4 \%$ ) (Fig. 1 ).

The first function separates primarily Longal from the other cultivars (means of the canonical variance $(\mathrm{MCV})$ : Aveleira $=-4.800$, Boaventura $=-4.410$, Judia $=-2.398 ;$ Longal $=11.607$, and revealed to be more powerfully correlated with $\alpha$-tocopherol, $\delta$ tocopherol, C15:0, LLLn, NDF, crude fat, PLP, PLLn and C18:3. The second function was able to separate Aveleira from Boaventura and Judia (MCV: Aveleira $=5.219 ; \quad$ Boaventura $=-3.817$; Judia $=-1.749$; Longal $=0.347$ ) and showed to be more correlated with LLL, OLO, water, $\gamma$-tocopherol, energy, ADF, crude protein, cellulose, carbohydrates, C22:0, C16:0, C18:0 and C18:2. The third function was essential to separate Boaventura and Judia (MCV: Aveleira $=-0.624 ; \quad$ Boaventura $=-2.590 ; \quad J u d i a=3.693 ; \quad$ Longal $=-0.479$ ), being more correlated with $\delta$-tocopherol, OLLn, $\gamma$ tocopherol, ash, POO, C20:0, C17:0, C16:1, OOO, LLO, C20:1, PLO, PLL and C18:1.

The model was based in experimental data of only ten $(\alpha-$ tocopherol, $\gamma$-tocotrienol, LLL, OLLn, $\delta$-tocopherol, $\gamma$-tocopherol, $\delta$-tocotrienol, PLLn, protein and 000 ) of the thirty-eight initial dependent variables and showed a very satisfactory classification performance allowing to correctly classifying $100 \%$ of the samples for the original groups as well as for the cross-validation procedure. Despite the efficacy of this analysis (all the cultivars clustered individually), the method was somehow difficult to apply, once it still demands the measurement of a large number of parameters. 


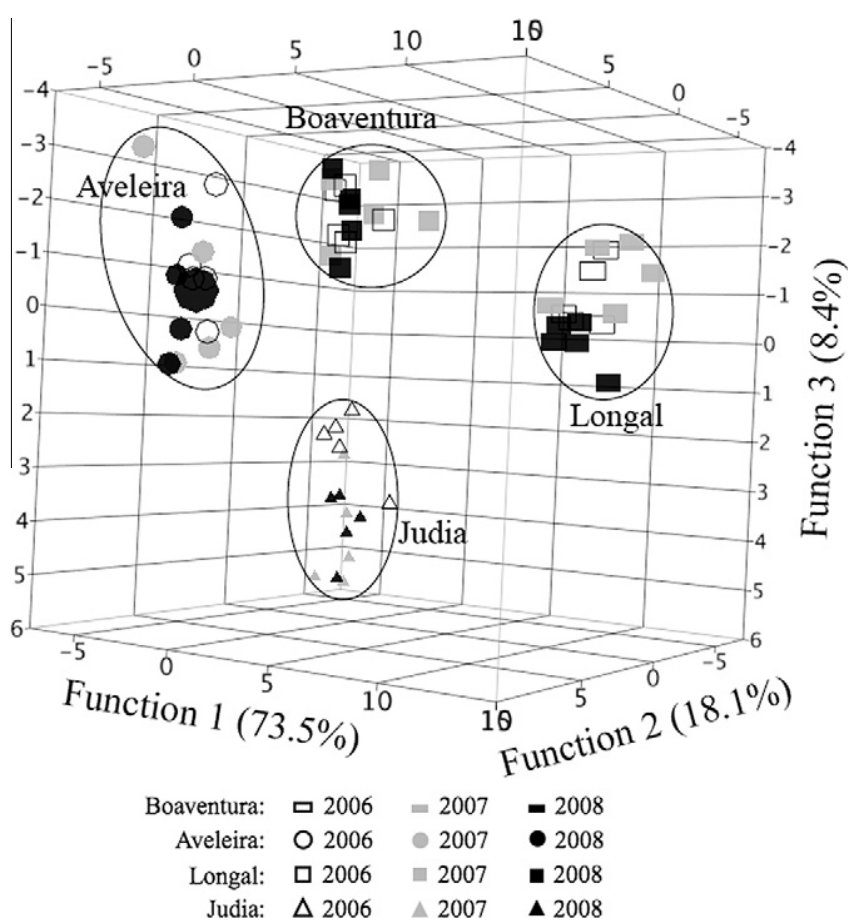

Fig. 1. Canonical analysis of chestnut cultivars based on all the parameters.

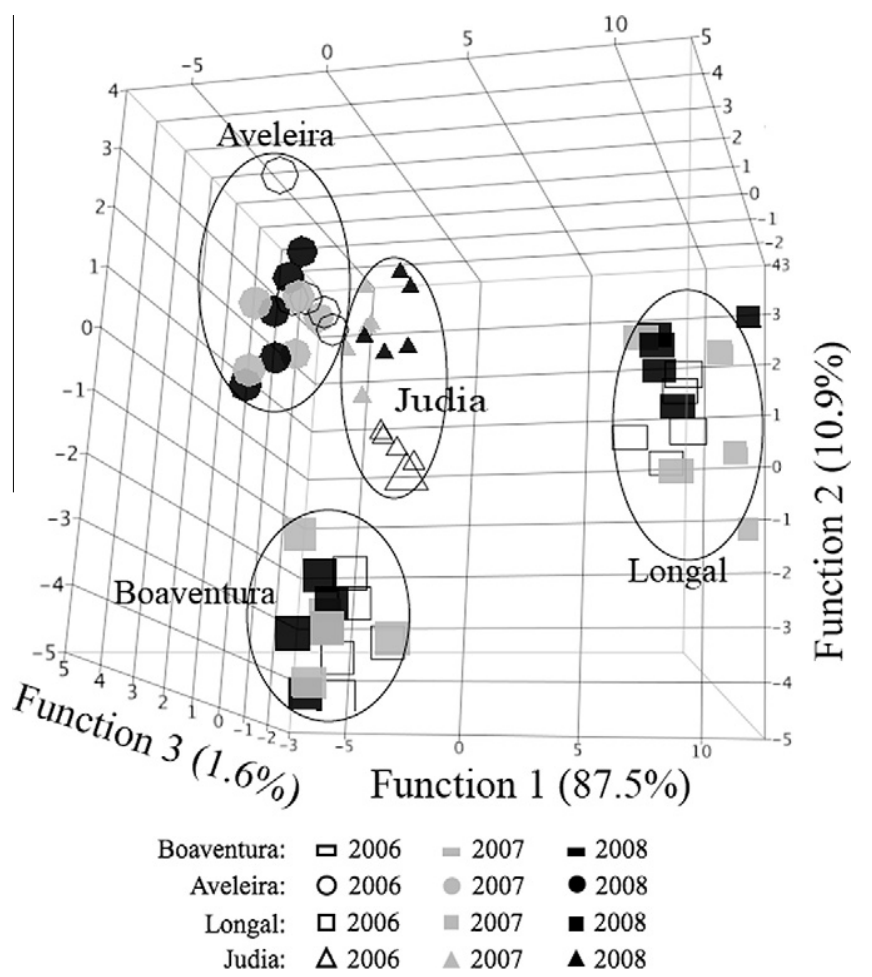

Fig. 2. Canonical analysis of chestnut varieties based on tocopherols profiles.

So, different sets of the obtained data for the assayed compounds were evaluated trough discriminant analysis to check their discriminant ability.

Regarding fatty acids, merely $45.0 \%$ ( $43.3 \%$ of cross validated groups) of original grouped cases were correctly classified; considering nutritional parameters, only $71.7 \%$ (63.3\% of cross validated groups) of original grouped cases were properly classified; for TAG, $88.3 \%$ (86.7\% of cross validated groups) of original grouped cases were correctly classified.
Finally, when the analysis was performed considering tocopherols profiles, the results were very satisfactory. In this case, the use of the stepwise LDA resulted in a discriminant model with three significant $(P<0.001$ for the Wilks' $\lambda$ test) discriminant functions. These three functions explained $100.0 \%$ of the variance of the experimental data (the first explained $87.5 \%$, the second $10.9 \%$ and the third 1.6\%) (Fig. 2).

The first function separates primarily Longal from the other cultivars (MCV: $\quad$ Aveleira $=-4.756 ; \quad$ Boaventura $=-3.034$; Judia $=-2.732$; Longal $=10.522$ ), and revealed to be more powerfully correlated with $\alpha$-tocopherol. The second function separates Boaventura from the other cultivars (MCV: Aveleira $=1.837$; Boaventura $=-3.594 ;$ Judia $=1.559$; Longal $=0.199$ ) and showed to be more correlated with $\gamma$-tocopherol, $\delta$-tocopherol and $\gamma$-tocotrienol. The third function was crucial to separate Aveleira and Judia (MCV: Aveleira $=1.075 ;$ Boaventura $=0.015 ;$ Judia $=-1.524$; Longal $=0.164$ ), being more correlated with $\delta$-tocotrienol. The model showed a very satisfactory classification performance also allowing to correctly classifying $100 \%$ of the samples for the original groups as well as for the cross-validation procedure.

\section{Conclusions}

The results obtained in all the assays seem to reveal statistical significant interaction effects among the two assayed factors (" $C$. sativa cultivars $\times$ harvesting year"). So, it is relatively unpredictable to define climatic conditions or genetically defined features as prevailing influence factor. This finding could have hindered the objective of define a specific assay that undoubtedly classifies a determined chestnut cultivar, a paramount feature considering authentication purposes. However, when LDA was applied to tocopherols contents, the results proved to be of utmost importance, since the assayed cultivars were completely separated. With a single, fast and reliable assay (tocopherols analysis coupled with LDA), any chestnut sample may be classified as belonging to one of these specific cultivars, conveying economical benefits.

This is particularly important in countries where chestnut production is dominated by a low number of cultivars. The chemical composition had already been used successfully to discriminate different chestnut cultivars (Sacchetti and Pinnavaia, 2005; Neri et al., 2010).

Furthermore, this work also represents a contribution to chestnut characterization. In this way, the data obtained can also be helpful in updating or creating databases and available composition tables concerning chestnut chemical composition, which could be useful in the guarantee of chestnut PDO authenticity. Characterization of chestnut cultivars is important in different fields from the nutritional point of view, technological processes and applications.

\section{Conflict of Interest}

The authors declare that there are no conflict of interest.

\section{Acknowledgement}

The authors are grateful to Fundação para a Ciência e Tecnologia (Portugal) for financial support to J.C.M. Barreira (SFRH/BD/29060/ 2006).

\section{References}

Adua, M., 1999. Sweet chestnut production and marketing in Italy. Acta Hortic. 494, 44-54. 
Agostinucci, K., Manfredi, T.G., Cosmas, A., Martin, K., Han, S.N., Wu, D., Sastre, J. Meydani, S.N., Meydani, M., 2002. Vitamin E and age alter liver mitochondrial morphometry. J. Anti-Aging Med. 5, 173-178.

Allard, J.P., Aghdassi, E., Chau, J., Tam, C., Kovacs, C.M., Salit, I.E., Walmsley, S.L., 1998. Effects of vitamin $\mathrm{E}$ and $\mathrm{C}$ supplementation on oxidative stress and viral load in HIV-infected subjects. AIDS 12, 1653-1659.

AOAC, 1995. Official methods of analysis, 16th ed., Association of Official Analytical Chemists, Arlington VA, USA.

Baraldi, C., Bodecchi, L.M., Cocchi, M., Durante, C., Ferrari, G., Foca, G., Grandi, M., Marchetti, A., Tassi, L., Ulrici, A., 2007. Chemical composition and characterization of seeds from two cultivars (pure and hybrid) of Aesculus hippocastanum. Food Chem. 104, 229-236.

Barreira, J.C.M., Alves, R.C., Casal, S., Ferreira, I.C.F.R., Oliveira, M.B.P.P., Pereira, J.A. 2009a. Vitamin E profile as a reliable authenticity discrimination factor between chestnut (Castanea sativa Mill.) cultivars. J. Agr. Food Chem. 57, 5524-5528.

Barreira, J.C.M., Casal, S., Ferreira, I.C.F.R., Oliveira, M.B.P.P., Pereira, J.A., 2009b. Nutritional, fatty acid and triacylglycerol profiles of Castanea sativa Mill. cultivars: a compositional and chemometric approach. J. Agr. Food Chem. 57, 2836-2842.

Borges, O., Gonçalves, B., Carvalho, J.L.S., Correia, P., Silva, A.P., 2008. Nutritional quality of chestnut (Castanea sativa Mill.) cultivars from Portugal. Food Chem. 106, 976-984.

Borges, O.P., Carvalho, J.S., Correia, P.R., Silva, A.P., 2007. Lipid and fatty acid of profiles of Castanea sativa Mill. chestnuts of 17 native Portuguese cultivars. J. Food Compos. Anal. 20, 80-89.

Bounous, G., 2005. The chestnut: a multipurpose for the new millennium. Acta Hortic. 693, 33-40.

Buchgraber, M., Ulberth, F., Emons, H., Anklam, E., 2004. Triacylglycerol profiling by using chromatographic techniques. Eur. J. Lipid Sci. Tech. 106, 621-648.

Camire, M.E., Dougherty, M.P., 2003. Raisin dietary fiber composition and in vitro bile acid binding. J. Agr. Food Chem. 51, 834-837.

De La Montaña Míguelez, J., Míguez Bernárdez, M., Garcia Queijeiro, J.M., 2004 Composition of varieties of chestnuts from Galicia (Spain). Food Chem. 84 (3), 401-404.

Desmaison, A., Marcher, M.H., Tixier, M., 1984. Changes in free and total amino acid composition of ripening chestnut seeds. Phytochemistry 23, 2453-2456.

Emken, E.A., Adlof, R.O., Gulley, R.M., 1994. Dietary linoleic acid influences desaturation and acylation of deuterium-labeled linoleic and linolenic acids in young adult males. Biochim. Biophys. Acta 1213, 277-288.

Fernandes, Â., Barreira, J.C.M., Antonio, A.L., Bento, A., Botelho, M.L., Ferreira, I.C.F.R., 2011. Assessing the effects of gamma irradiation and storage time in energetic value and in major individual nutrients of chestnuts. Food Chem. Toxicol. 49, 2429-2432.

Ferreira-Cardoso, J.V., Fontaínhas-Fernandes, A.A., Torres-Perreira, J.M.G., 1993. Nutritive value and technological characteristics of Castanea sativa Mill. fruits Comparative study of some Northeastern Portugal cultivars. In: Proceedings of International Congress on Chestnut, Spoleo, 445-449.

Ferreira-Cardoso, J.V., Rodrigues, L., Gomes, E.F., Sequeira, C.A., Torres-Perreira, J.M.G., 1999. Lipid composition of Castanea sativa Mill. fruits of some native Portuguese cultivars. Acta Hortic. 494, 138-138.

Ferreira-Cardoso, J.V., Torres Pereira, J.M.G., Sequeira, C.A., 2005. Effect of year and cultivar on chemical composition of chestnuts from northeastern Portugal. Acta Hortic. 693, 271-277.

Gonçalves, B., Borges, O., Soares Costa, H., Bennett, R., Santos, M., Silva, A.P., 2010 Metabolite composition of chestnut (Castanea sativa Mill.) upon cooking: proximate analysis, fibre, organic acids and phenolics. Food Chem. 122, 154160.

Goulão, L., Valdiviesso, T., Santana, C., Oliveira, C.M., 2001. Comparison between phenetic characterization using RAPD and ISSR markers and phenotypic data of cultivated chestnut (Castanea sativa Miller). Genet. Resour. Crop Ev. 48, 329338.

Gunstone, F.D., Hamilton, R.J., Padley, F.B., Ilyas-Qureshi, M., 1965. Glyceride studies. V. The distribution of unsaturated acyl groups in vegetable triglycerides. J. Am. Oil Chem. Soc. 42, 965-970.
International Standardization Organization 5509, 2000. Animal and vegetable fats and oils - Preparation of methyl esters of fatty acids.

Itoh, N., Masuo, Y., Yoshida, Y., Cynshi, O., Jishage, K., Niki, E., 2006. $\gamma$-Tocopherol attenuates MPTP-induced dopamine loss more efficiently than $\alpha$-tocopherol in mouse brain. Neurosci. Lett. 403, 136-140.

Jiang, Q., Elson-Schwab, I., Courtemanche, C., Ames, B.N., 2000. Gamma-tocopherol and its major metabolite, in contrast to alpha-tocopherol, inhibit cyclooxygenase activity in macrophages and epithelial cells. Proceed. Natl. Acad. Sci. USA 97, 11494-11499.

Kamm, W., Dionisi, F., Hischenhuber, C., Engel, K., 2001. Authenticity assessment of fats and oils. Food Rev. Int. 17, 249-290.

Kok, T.M.C.M., Zwingman, I., Moonen, E.J., Schilderman, P.A.E.L., Rhijnsburger, E. Haenen, G.R.M.M., Kleinjans, J.C.S., 2003. Analysis of oxidative DNA damage after human dietary supplementation with linoleic acid. Food Chem. Toxicol. $41,351-358$.

Kormsteiner, M., Wagner, K.H., Elmadfa, I., 2006. Tocopherols and total phenolics in 10 different nut types. Food Chem. 98, 381-387.

Künsch, U., Scharer, H., Conedera, M., Sassella, A., Jermini, M., Jelmini, G., 1999. Quality assessment of chestnut fruits. Acta Hortic. 494, 119-127.

Lee, C.-Y.J., Wan, J.M.-F., 2000. Vitamin E supplementation improves cell-mediated immunity and oxidative stress of Asian men and women. J. Nutr. 130, 29322937.

López, A., García, P., Garrido, A., 2008. Multivariate characterization of table olives according to their mineral nutrient composition. Food Chem. 106, 369-378.

Maroco, J., 2003. Análise Estatística, com utilização do SPSS. Edições Sílabo, Lisboa, Portugal.

McKenna, M.C., Hubbard, V.S., Aeri, J.G., 1985. Linoleic acid absorption for lipid supplements in patients with cystic fibrosis with pancreatic insufficiency and in control subjects. J. Pediatr. Gastr. Nutr. 4, 45-48.

Neri, L., Dimitri, G., Sacchetti, G., 2010. Chemical composition and antioxidant activity of cured chestnuts from three sweet chestnut (Castanea sativa Mill.) ecotypes from Italy. J. Food Compos. Anal. 23, 23-29.

Pereira-Lorenzo, S., Díaz-Hernández, M.B., Ramos-Cabrer, A.M., 2006a. Use of highly discriminating morphological characters and isozymes in the study of Spanish chestnut cultivars. J. Am. Soc. Hortic. Sci. 131, 770-779.

Pereira-Lorenzo, S., Ramos-Cabrer, A.M., Díaz-Hernández, M.B., Ciordia-Ara, M., Ríos-Mesa, D., 2006b. Chemical composition of chestnut cultivars from Spain. Sci. Hortic. 107, 306-314.

Pinnavaia, G.G., Pizzirani, S., Severini, C., Bassi, D., 1993. Chemical and functional characterization of some chestnut varieties. In: Proceedings of the $1 \mathrm{st}$ International Congress on Chestnut, University of Perugia, Perugia.

Portuguese Government Legislation, 1994: Decreto Normativo 44/94, from February 3rd. Ministério da Agricultura, Desenvolvimento Rural e Pescas.

Rencher, A.C., 1995. Methods of Multivariate Analysis. John Willey, New York.

Robertson, J.B., Van Soest, P.J., 1981. The detergent system analysis and its application to human foods. In: James, W.P.T., Theander, O. (Eds.), The Analysis of Dietary Fiber in Food, Marcel Dekker, vol. 3. Inc, New York, pp. 123-158.

Sacchetti, G., Pinnavaia, G.G., 2005. Compositional characteristics of some chestnut biotypes of Emiliano-Romagnolo Apennine. Acta Hortic. 693, 241-245.

Senter, S.D., Payne, J.A., Miller, G., Anagnosakis, S.L., 1994. Comparison of total lipids, fatty acids sugars and non-volatile organic acids in nuts from four Castanea species. J. Sci. Food Agr. 65 (2), 223-227.

Simopoulos, A.P., 1991. Omega-3 fatty acids in health and disease and in growth and development. Am. J. Clin. Nutr. 54, 438-463.

Vasconcelos, M.C.B.M., Bennett, R.N., Rosa, E.A.S., Ferreira-Cardoso, J.V., 2010. Composition of European chestnut (Castanea sativa Mill.) and association with health effects: fresh and processed products. J. Sci. Food Agr. 90, 1578-1589.

Vasconcelos, M.C.M.B., Bennet, R.N., Rosa, E.A.S., Cardoso, J.V.F., 2007. Primary and secondary metabolite composition of kernels from three cultivars of Portuguese chestnut (Castanea sativa Mill.) at different stages of industrial transformation. J. Agric. Food Chem. 55, 3508-3516.

Vaughan, J.G., Geissler, C.A., 1997. The New Oxford Book of Food Plants. Oxford University Press, New York. 